\title{
Active chronic hepatitis and febrile panniculitis
}

\author{
A K BANERJEE, S L GRAINGER, D R DAVIES, AND R P H THOMPSON \\ From the Gastrointestinal Laboratory, The Rayne Institute and Department of Histopathology, St Thomas' \\ Hospital, London
}

\begin{abstract}
summary Two patients with autoimmune hepatitis B negative chronic hepatitis and febrile panniculitis are described. On each occasion the panniculitis responded to increasing the doses of prednisolone.
\end{abstract}

Active chronic hepatitis is associated with numerous systemic complications, ' - but rarely with febrile panniculitis. Such an association in two patients is described here.

\section{Case reports}

PATIENT 1

A 34 year old woman presented with progressive, painful bilateral weakness of the thigh muscles. Her previous history included hepatitis at the age of 12 , which progressed to histologically proven hepatitis $B$ negative, antinuclear antibody-positive, active chronic hepatitis. Subsequently, she had one episode of arthralgia and pericarditis at the age of 17 . From the age of 24 pyoderma gangrenosum had intermittently affected the hands and lower limbs, but there were long periods of quiescence.

At the time of admission she was receiving prednisolone $7.5 \mathrm{mg}$ and azathioprine $50 \mathrm{mg}$ daily. Examination revealed a pyrexia of $38.2^{\circ} \mathrm{C}$, and swollen thighs with superficial areas of marked tenderness of the lateral surfaces. There was severe bilateral pain and loss of power on hip and knee flexion and extension. There was, as previously, clinical hepatosplenomegaly (Fig. 1).

Investigations on admission included: sedimentation rate $60 \mathrm{~mm} / \mathrm{h}$, alanine aminotransferase $30 \mathrm{U} / \mathrm{l}$ (normal 20), bilirubin $27 \mu \mathrm{mol} / \mathrm{l}$ (19), creatine kinase normal, antinuclear antibody 1 in 80 with diffuse IgG; smooth muscle antibody 1 in 80 . T/B lymphocyte cell ratio normal, with lymphopenia $\left(0 \cdot 4 \times 10^{\circ} / 1\right)$.

During the next two weeks there was intermittent pyrexia of up to $38 \cdot 8^{\circ} \mathrm{C}$, with negative blood cultures.

Address for correspondence: Dr R P H Thompson, St Thomas' Hospital. London SEI 7 EH.

Accepted for publication 29 November 1988.
Electromyographic studies showed no neuropathy or myopathy, but a surgical biopsy specimen taken from an area of tenderness in the right vastus lateralis showed normal striated muscle but a chronic nonspecific panniculitis in the adipose tissue.

The pain and weakness rapidly improved after increasing the dose of prednisolone to $30 \mathrm{mg}$ daily and the patient was discharged with only slight residual weakness and wasting of both quadriceps. At follow up 12 months later the patient was pain free with no weakness on prednisolone $2.5 \mathrm{mg} /$ day.

\section{PATIENT 2}

A 38 year old woman presented in 1971 with jaundice and pruritus, and the histological appearances of a liver biopsy specimen showed active chronic hepatitis. The serum later contained smooth muscle antibody

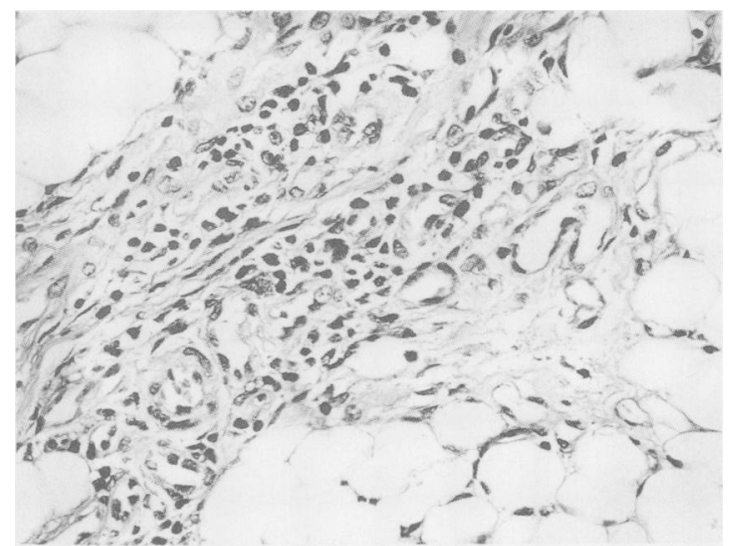

Fig. 1 Section of muscle biopsy specimen, which shows, damaged adipocytes with a chronic inflammatory reaction in the interstitial tissue. 


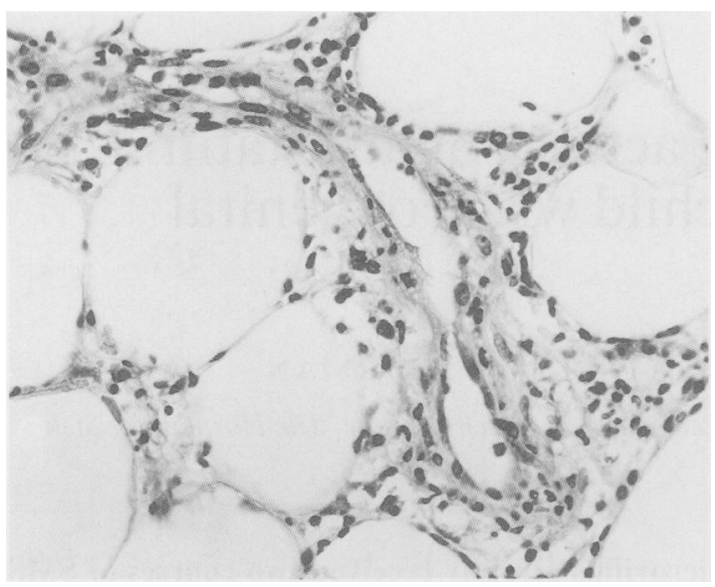

Fig. 2 Section of subcutaneous tissue showing inflammation in a blood vessel wall in the subcutaneous tissue.

$(++)$ and antinuclear factor $(\operatorname{IgG} 1$ in 1250 ; $\operatorname{IgM} 1$ in $160)$, and $\operatorname{Ig} A$ levels were raised. Hepatitis B surface antigen was absent. She made a rapid response to oral prednisolone therapy.

Four years later, at the age of 42 and during withdrawal of corticosteroids, but while on $3.5 \mathrm{mg}$ cyclophosphamide daily, she developed painful, itchy, purpuric, indurated papules, initially on the ankles but spreading proximally to the buttocks. This was followed by a relapse of her liver disease (bilirubin $12 \mu \mathrm{mol} / \mathrm{l}$, aspartate aminotransferase 225

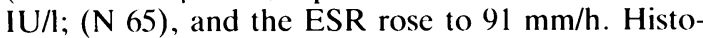
logical examination of a surgical biopsy specimen of a nodule revealed a non-specific panniculitis with subcutaneous vasculitis (Fig. 2). This rapidly responded to increase of the dose of prednisolone, and has not recurred.

Since then she has experienced polyarthritis and toxic epidermal necrolysis, possibly related to carbamazepine, and is presently well without pain or weakness on azathioprine $75 \mathrm{mg}$ daily alone.

\section{Discussion}

Autoimmune active chronic hepatitis is associated with a varicty of organ specific vasculitic diseases, ${ }^{2}$ and skin changes that have been reported include acne, erythematous lesions, lupus like changes, papular eruptions, purpura, striae, urticaria, allergic capillaritis and pyoderma gangrenosum.

Our first patient not only had arthralgia, pericarditis, and pyoderma gangrenosum, but also latterly a febrile panniculitis, while the second patient experienced polyarthritis, epidermal necrolysis and panniculitis. The biopsy specimens were necessarily small, but the histological appearances of panniculitis were diagnostic.

Panniculitis, of which Weber-Christian disease is one part of a spectrum, is associated with abnormalities of immune function. ${ }^{3}$ One case of panniculitis associated with viral hepatitis has been reported in a 34 year old man, ${ }^{4}$ but this was autoantibody negative acute viral hepatitis, and the panniculitis presented during the prodromal period and resolved after treatment with indomethacin. Cook et al recorded a single patient with Weber-Christian disease and active chronic hepatitis, but gave no details.

We report, therefore, this association of panniculitis to add to the spectrum of associated autoimmune systemic conditions. It responds readily to prednisolone, and leaves no longterm sequelac.

\section{References}

1 Golding PL. Smith M, Williams R. Multisystem involvement in chronic liver disease. Am J Med 1973; 55: 772 82.

2 Mistilis SP, Blackburn CRB. Active chronic hepatitis. Am J Med 1970; 48: 484-95.

3 Allen-Mersh TG. Weber-Christian panniculitis and autoimmune discase. J Clin Pathol 1976; 29: 144.

4 Fowler JF, Callen JP. Panniculitis associated with hepatitis. ('utis 1983; 32: 543-7.

5 Cook GC. Mulligan R. Sherlock S. Controlled prospective trial of corticosteroid therapy in active chronic hepatitis. Q J Med 1971; 40: 150-85. 